\title{
SMALLHOLDER FARMERS' PERCEPTION ON TOMATO (Solanum lycopersicum) SEEDLING TECHNOLOGIES IN THE NORTH WEST ZONE OF NIGERIA
}

\author{
Isaiah Gabriel*, Frank Olajuwon, Blessing Michael
}

Syngenta Foundation for Sustainable Agriculture-Nigeria.

ART ICLE INF O

\section{Article History}

Received: January 18, 2020

Revised: March 12, 2020

Accepted: April 27, 2020

\section{Keywords}

Smallholders

Tomato

Seedlings

Technology

Perception

Northwest Nigeria
A B S T R A C T

The research was funded by Syngenta Foundation for sustainable Agriculture, Nigeria to ascertain Farmer's perception on tomato seedlings technology in North West Zone of Nigeria. Multistage sampling technique was employed for the selection of One hundred and ninety-five (195) producers of Tomato in Kano and Jigawa States. Data were collected with the aid of a questionnaire. Data obtained were analysed using mean, standard deviation, coefficient of variation, charts, and graphs. The results of the study revealed that the producers of tomato had a mean age of 38 years, majorly males (86\%) with secondary school education (32\%), married (88\%) with mean household size of 11 persons, mean farming experience, vegetable experience and tomato production experience of 18,13 and 12 years respectively, mean land cultivated 3ha and mean tomato farm size of 2 ha. Maize, sorghum, and rice are the three most cultivated crops by the farmers with tomato and onions as major vegetables. Plum tomato (UTC) variety (34\%) is the most widely cultivated during both dry and wet seasons. The study further revealed that $82 \%$ of the farmers used recycled seeds to produce seedlings, $88 \%$ of the farmers had no extension and advisory service training, 59\% made use of seedlings for planting with Plum tomato (UTC) as the common variety, 95\% are interested in buying and selling seedlings, and $98 \%$ propagated their seeds in the open field. Therefore, it is recommended from the study that public and private's sector at all levels should strengthen extension service systems to increase farmers' knowledge and understanding of new tomato production technology-through provision of tomato seedlings technology, frequent trainings and marketing demos establishment to showcase this new innovation, Seed companies should ensure that seed packages contain recommended agronomic practices for all round effectiveness.

Corresponding Author: Isaiah Gabriel

Email: isaiah.gabriel@Syngenta.com

(C) The Author(s) 2021.

\section{INTRODUCTION}

According to FAO (2021), agriculture remains the largest sector of the Nigerian economy and employs two-thirds of the entire labour force. The production hurdles have significantly stifled the performance of the sector, the main factors undermining production include reliance on rain-fed agriculture, smallholder land holding, and low productivity due to poor planting material, low fertilizer application, and a weak agricultural extension system amongst others. Many smallholders have no access to appropriate farming knowledge and technology because of their limited production volume as well as weak links to both input and output market (Syngenta Foundation for Sustainable Agriculture, 
2020). One of the major goals of Nigerian agriculture development programmes and policies is the transition from low productivity subsistence agriculture to a high productivity agro industry economy through improved technology adoption. That is, shift from traditional methods of production to new, science-based methods of production which include new technological components and/or even new farming systems (Hassen, 2014). Most of the dry season market gardeners that grow tomatoes and regard it as the principal crop are engaged in smallholding agriculture, attempt to address the smallholder farmers are often geared toward improving agricultural practices as a means of increasing productivity, efficiency and, finally income (Obayelu et al., 2016).

Most vegetables are low in starch content and are a good source of phytonutrients. They serve as roughage, which promote digestion, and prevent constipation. Vegetable crops not only improve the nutritional quality of diets, the production of vegetables under irrigation and their marketing provides many people with employment in the dry season, it constitutes a major component of the country's food sector and it also occupies a significant position in the total per capita calorie intake of most Nigerians (Badmus and Olufolaji, 2013).

National Agricultural Research Institutions such as National Cereals Research Institute (NRCI) Badeji, National Cereals Research Institute (NCRI), Umudike, International Institute of Tropical Agriculture (IITA), Universities and other research institutions like ICRISAT are in the forefront of developing and applying new technologies. Meena and Punjabi (2012) asserted that the assessment of the adoption of the technologies have moved from just using dichotomous choice to examining the intensity of adoption, addressing the simultaneity of adoption of different components of a technology package, and contextualizing adoption decisions within social, cultural and institutional environments.

Over the last decade, the production of fresh tomatoes in Nigeria has grown by $25 \%$ from 1.8 million tonnes to an estimated 2.3 million tonnes. However, this growth has been primarily facilitated by continuous increase in the harvested area for tomatoes from 265,000 hectares to 668,292 hectares in the same period. However, between 2006 and 2016, tomato yields have remained very low at an average of 5.47 tonne/ha relative to the world average yield of 38.1 tonne/ha. The use of old seedling varieties, pest and weed invasion and low soil fertility has contributed to the low tomato yield (Ugonna et al., 2015). The lack of a good variety of seeds to buy, the practice as well as the use direct seedlings during tomato propagation is a threat to tomato farming and to the economy in general.

One of the major problems of agricultural production in the Northern region of Nigeria is low level of agricultural technological adoption. Majority of dwellers especially in the rural areas are dependent on agriculture for their livelihood and sustenance. Low agricultural productivity, production and adoption of new and improved technologies have resulted into economic deprivation and low standard of living

The objectives of the study are to (1) Identify the socioeconomic characteristics of tomato farmers (2) identify the agronomic practices carried out by smallholders in the area. (3) Ascertain farmers' awareness and adoption of tomato seedlings technology. (4) Ascertain farmers access to extension and advisory services and (5) evaluate farmer's perception on tomato seedlings technology.

\section{METHODOLOGY}

Syngenta Foundation for Sustainable AgricultureNigeria funded this research work in two States in the North Western part of Nigeria, namely: Kano and Jigawa. These States are considered representative in terms of biophysical characteristics and high agricultural production activities. In addition, these States have a high agricultural production potential, they were selected based on their high concentration on tomato production in the region with Kano being the most successful in Nigeria (Maiangwa et al., 2010).

Multistage sampling techniques was used for the study. The first stage involves a purposeful selection of Kano and Jigawa States based on study and careful observation of tomato seedling production in North west, Nigeria. Twelve local Governments were purposely selected with Nine (9) local governments from Kano State and Jigawa state with three (3) local governments, afterwards 13 communities were randomly chosen based on the intensity and concentration of tomato production in those areas. Finally, Random sampling technique was used in selecting 15 farmers from each community with the help and assistance of community opinion leaders and enumerators. Descriptive statistics which include, mean, frequency, percentages, standard deviation, coefficient of variation, charts and graphs 
were used to analyse the data on socio economic characteristics of farmers, good agronomic practices, awareness and adoption of agricultural technology and perception of farmers on tomato seedling technology. Model Specification

Coefficient of Variation (C.V) $=\frac{\text { Standard deviation }}{\text { Mean }} \times 100$

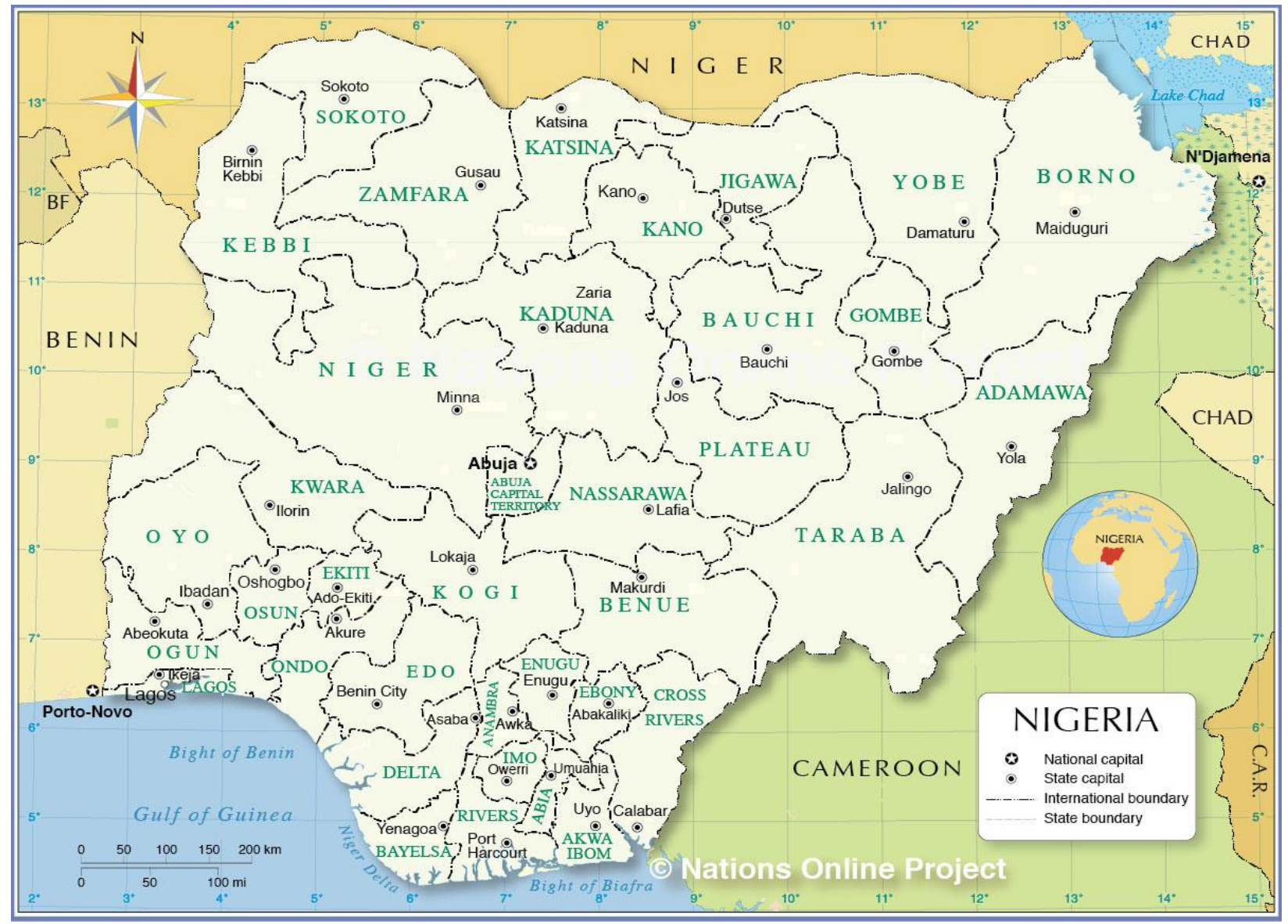

Figure 1. Map of Nigeria showing Northwest Zone.

Table 1. Sampling frame.

\begin{tabular}{|c|c|c|c|c|}
\hline $\mathrm{S} / \mathrm{N}$ & State & LGA & Community & Sampling size \\
\hline \multirow[t]{10}{*}{1.} & Kano & Bichi & Mazarawa'aawa & 15 \\
\hline & & Tofa & Yansabo & 15 \\
\hline & & Bagwai & Bauje & 15 \\
\hline & & Dawakin kudu & Kofar arewa & 15 \\
\hline & & Makoda & Gawan bature & 15 \\
\hline & & Dawakin tofa & Madachi & 15 \\
\hline & & Kura & Dan Hassan & 15 \\
\hline & & Bunkure & Tugugu & 15 \\
\hline & & Minjibir & Wasai & 15 \\
\hline & & Dawakin tofa & Yanshado & 15 \\
\hline \multirow[t]{3}{*}{2} & Jigawa & Birnin Kudu & Juwan tudu & 15 \\
\hline & & Dutse & Langwani & 15 \\
\hline & & Kirikasama & Turabu & 15 \\
\hline
\end{tabular}


Table 2. Socio-economic attributes of the respondents.

\begin{tabular}{lcccccc}
\hline Variables & $\mathrm{f}$ & $\%$ & Minimum & Maximum & Mean \pm Std. Dev. & C.V $\%$ \\
\hline Age & & & 19 & 65 & $38 \pm 10.22$ & 26 \\
\hline Household size & & & 1 & 42 & $11 \pm 6.948$ & 65 \\
\hline Farming experience & & 2 & 50 & $18 \pm 10.614$ & 59 \\
\hline Vegetable experience & & & 1 & 43 & $13 \pm 8.615$ & 65 \\
\hline Tomato experience & & 1 & 40 & $12 \pm 8.103$ & 68 \\
\hline Total land cultivated & & & 1 & 27 & $3.45 \pm 3.541$ & 100 \\
\hline Tomato farm size & 167 & 86 & & 15 & $1.67 \pm 1.627$ & 100 \\
\hline Gender & 28 & 14 & & & & \\
\hline Male & & & & & & \\
Female & 17 & 9 & & & & \\
\hline Marital status & 171 & 88 & & & & \\
\hline Single & 1 & 1 & & & & \\
Married & 6 & 3 & & & & \\
Divorced & & & & & \\
Widowed & 180 & 97 & & & \\
\hline Occupation & 3 & 2 & & & \\
\hline Farming only & 2 & 1 & & & & \\
Agro retailer & & & & & \\
Others & 56 & 29 & & & & \\
\hline Education & 63 & 32 & & & & \\
\hline Primary & 29 & 15 & & & & \\
Secondary & 47 & 24 & & & & \\
Tertiary & & & & & & \\
Quranic & & & & & & \\
\hline
\end{tabular}

\section{RESULTS AND DISCUSSION}

As shown in Table 2, it is observed that the average age of farmers in the area is 38 years, showing that most of the farmers are not aged hence it is expected that more strength is put into farming. In addition to this, the coefficient of variation for the mean age which is $26 \%$ shows that there is not much dispersion from the mean age, explaining that the farmers are still in their active age. The mean household size is 11 with $65 \%$ coefficient of variation. However, the mean household size of 11 individuals was far beyond the national average of 4.7 reported by National Population Commission (NPC, 2018). High number of household size could be since tomato producers in the study area are polygamous showing how large number of people lives on the income from farming. This also shows that the household can serve as labour for the farmers. Meanwhile the experience in farming explains that the farmers have an average farming experience of 18 years, vegetable farming experience of 13years and tomato farming experience of 12 years, showing that the farmers can weather/survive any unfavourable conditions in farming. Olayemi et al. (2011) in a separate study posited that the farmers' level of experience shows that they were vast in the system and that the elderly ones stays long on farming because of its profitability. The average land cultivated, and tomato farm size indicates subsistence farming, hence showing that the farmer from the area falls under the group of smallholder farmers. As shown in Table 2, majority (88\%) were married. This shows that agricultural production in the area is an enterprise of married individuals, who are seen to be responsible according to societal standards (Onubuogu et al., 2013). The implication of the finding is that married farmers would be more involved in sustainable and efficient tomato production than their single counterpart. Since they have easy access to production variables such as farmland and large family size which are traditionally owned and provided by household heads (husbands). Also $86 \%$ of the farmers are males, only $14 \%$ of the females in the area are involved in farming, by this there is every need to arrange programmes which will enlighten females to get involved in farming. This result agrees with Awagu et al. (2014) who posited that Vegetable farming in Kano state is gender specific as $100 \%$ of the respondent conducted 
in their study are men. This finding is traceable to the religion and cultural background of the people of the Northern States. The major occupation of the people in the area happens to be farming with $97 \%$ involved in farming only. Other involvements are agro-retailing and others with $2 \%$ and $1 \%$ respectively. The educational level of the farmers in the area shows that the farmers are not altogether illiterates having different levels of education. However, based on this it can be deduced that $32 \%$ of the farmers has secondary level education, $29 \%$ has only primary education, $15 \%$ got up to tertiary level education and the remaining $24 \%$ of the farmers had Quranic education. With such levels of education, there will be no constraint in communicating with the farmers especially in areas of training. It will also be easy for farmers to get market information, new innovations etc.

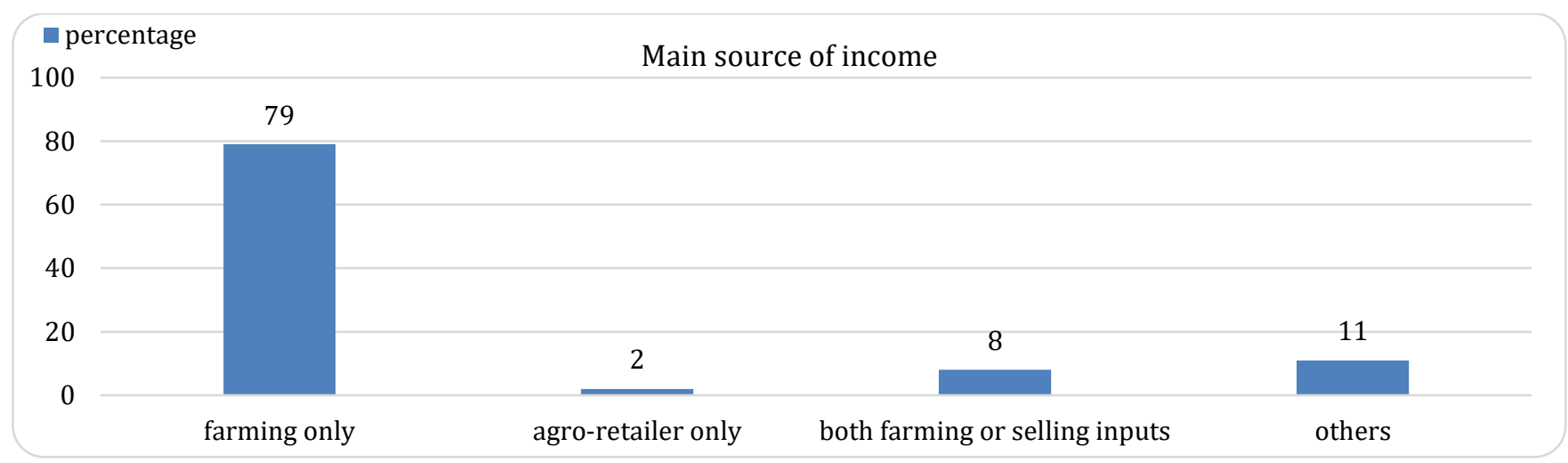

Figure 2. Main sources of income for respondents.

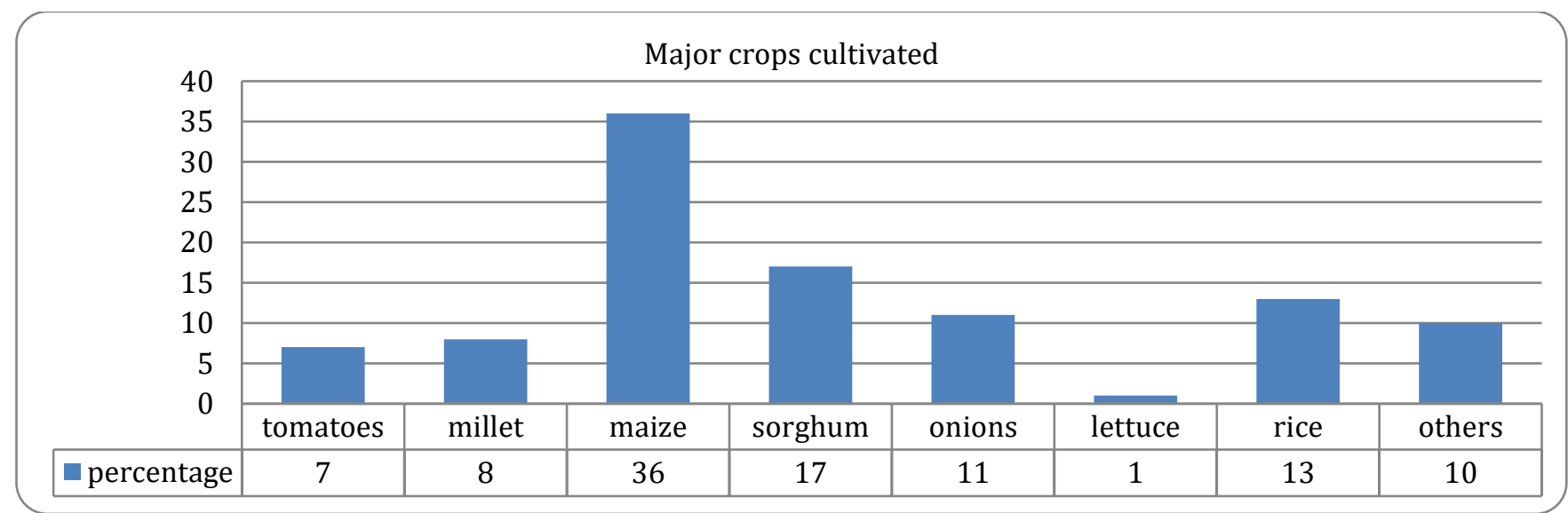

Figure 3. Major crops cultivated by respondents.

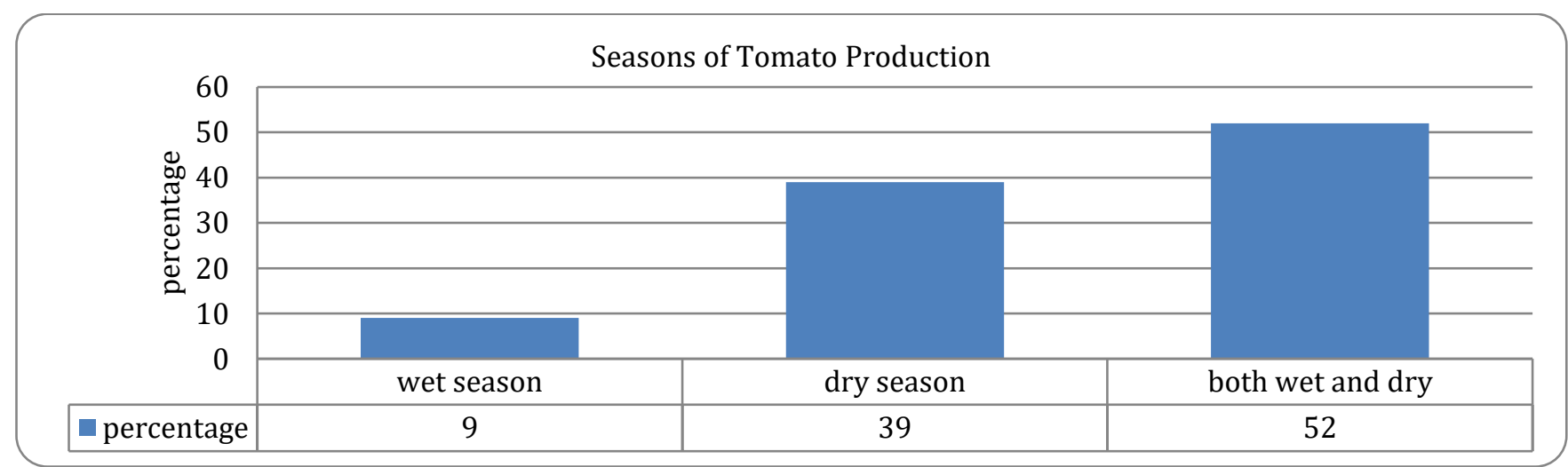

Figure 4. Seasons of tomato production. 
Tomato variety usage

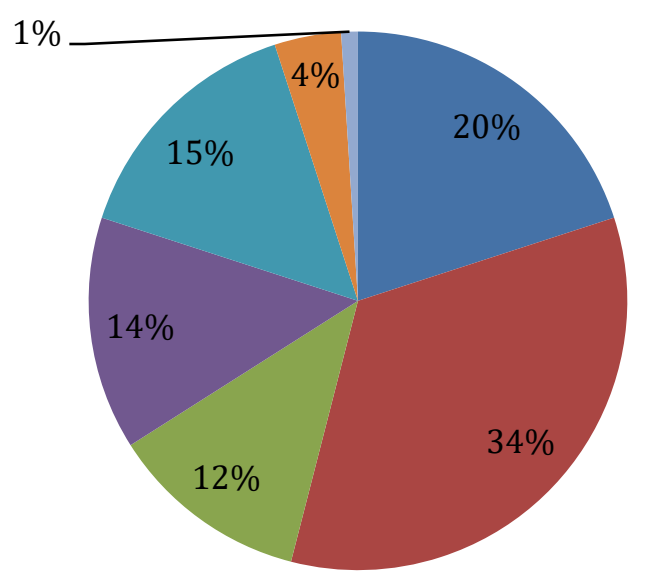

- Roma
- UC
- Grafton
- Technism
- Chibili
UCUB
Chimande

Figure 5. Tomato variety usage.

\section{Tomato Seedlings Planting}

Produce the seedling using recycled seeds

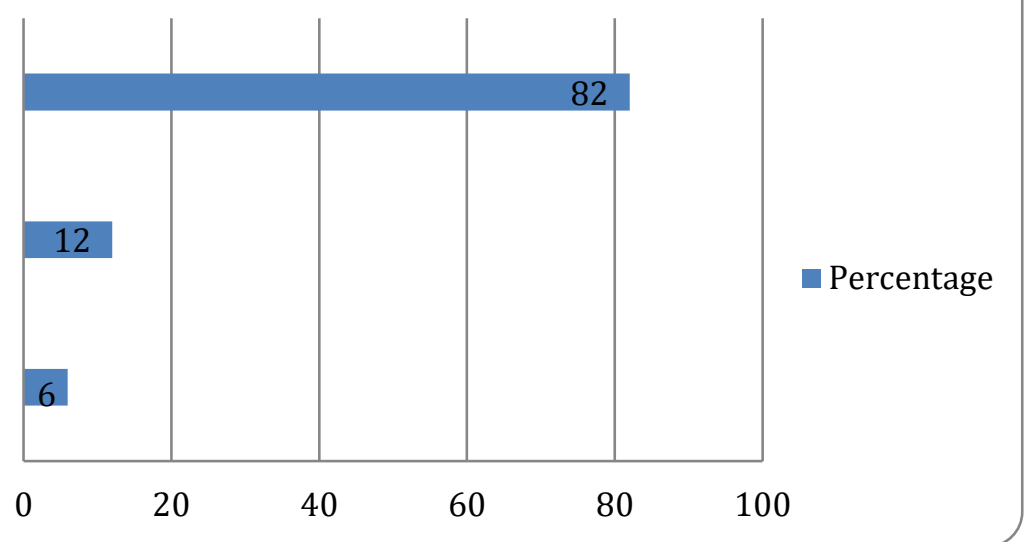

Figure 6. Tomato seedlings planting.

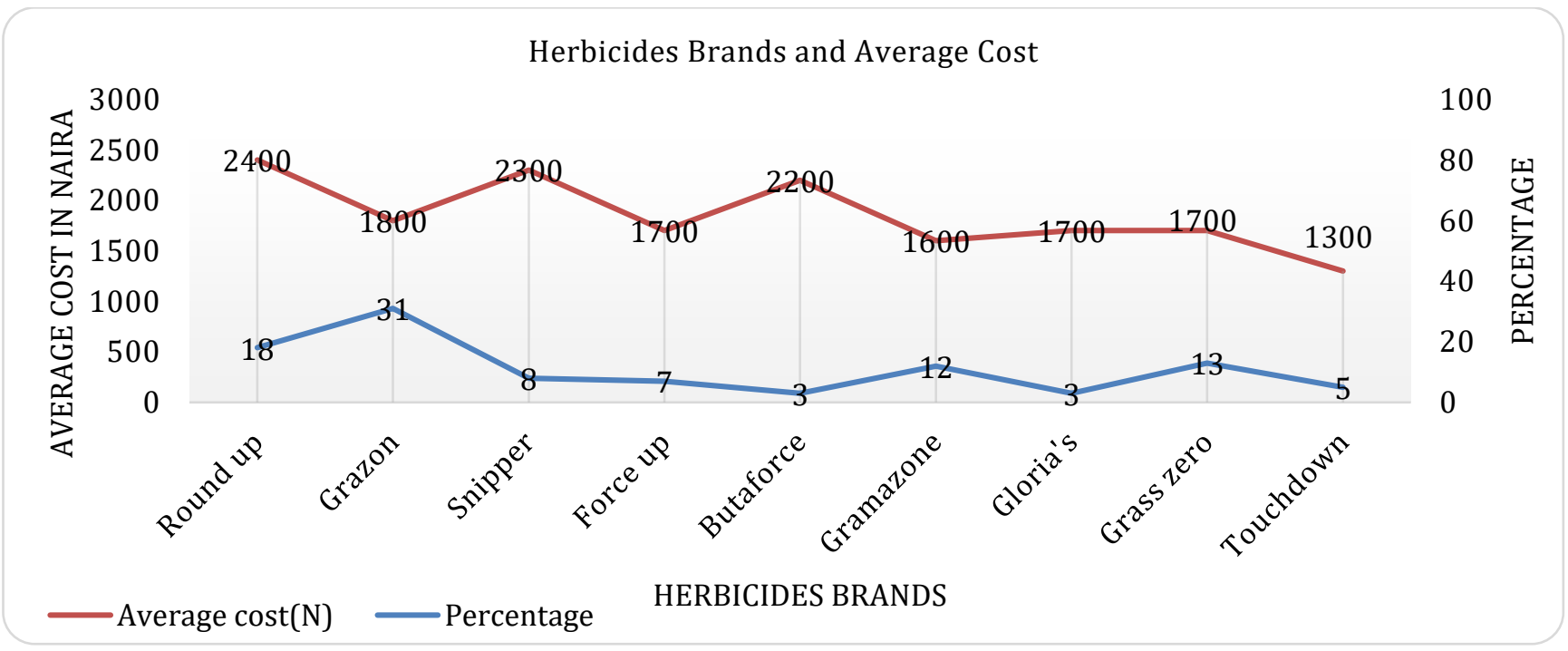

Figure 7. Herbicide brands and average cost. 


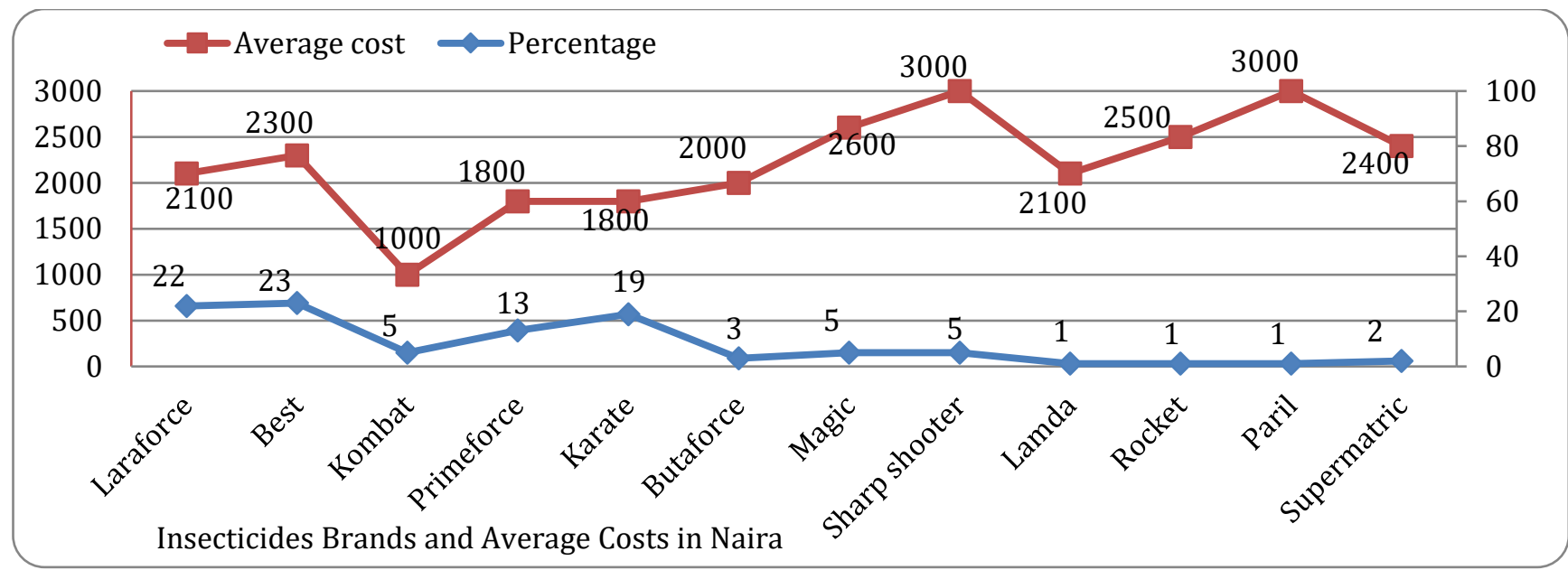

Figure 8. Insecticides brands and average cost.

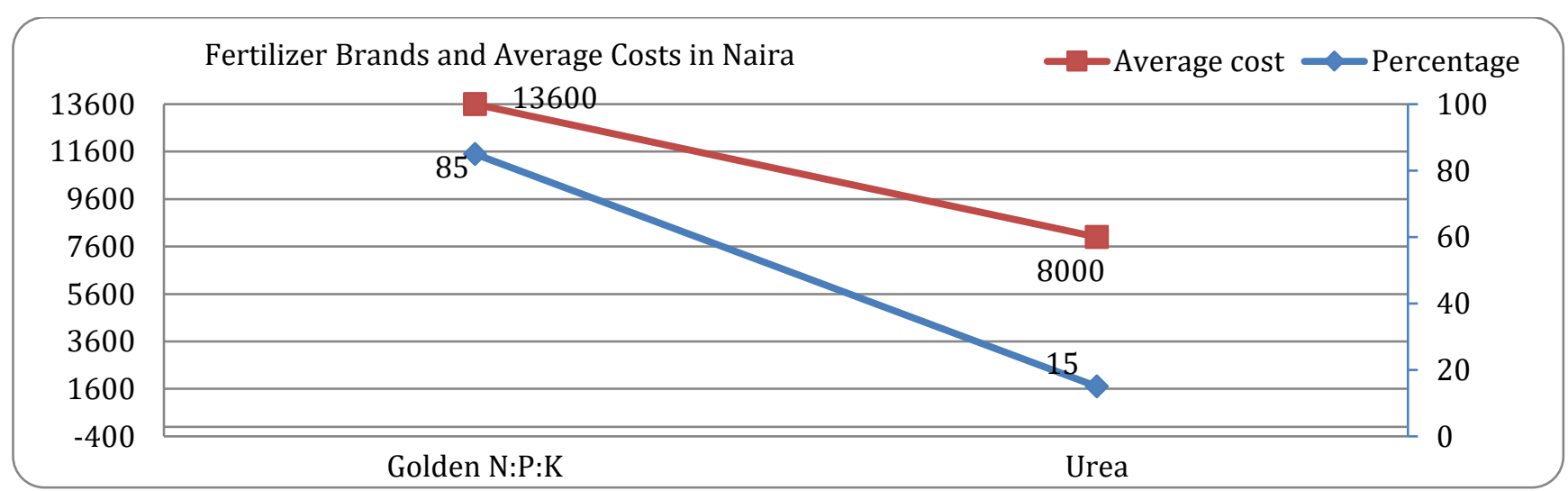

Figure 9. Fertilizer brands and average cost.

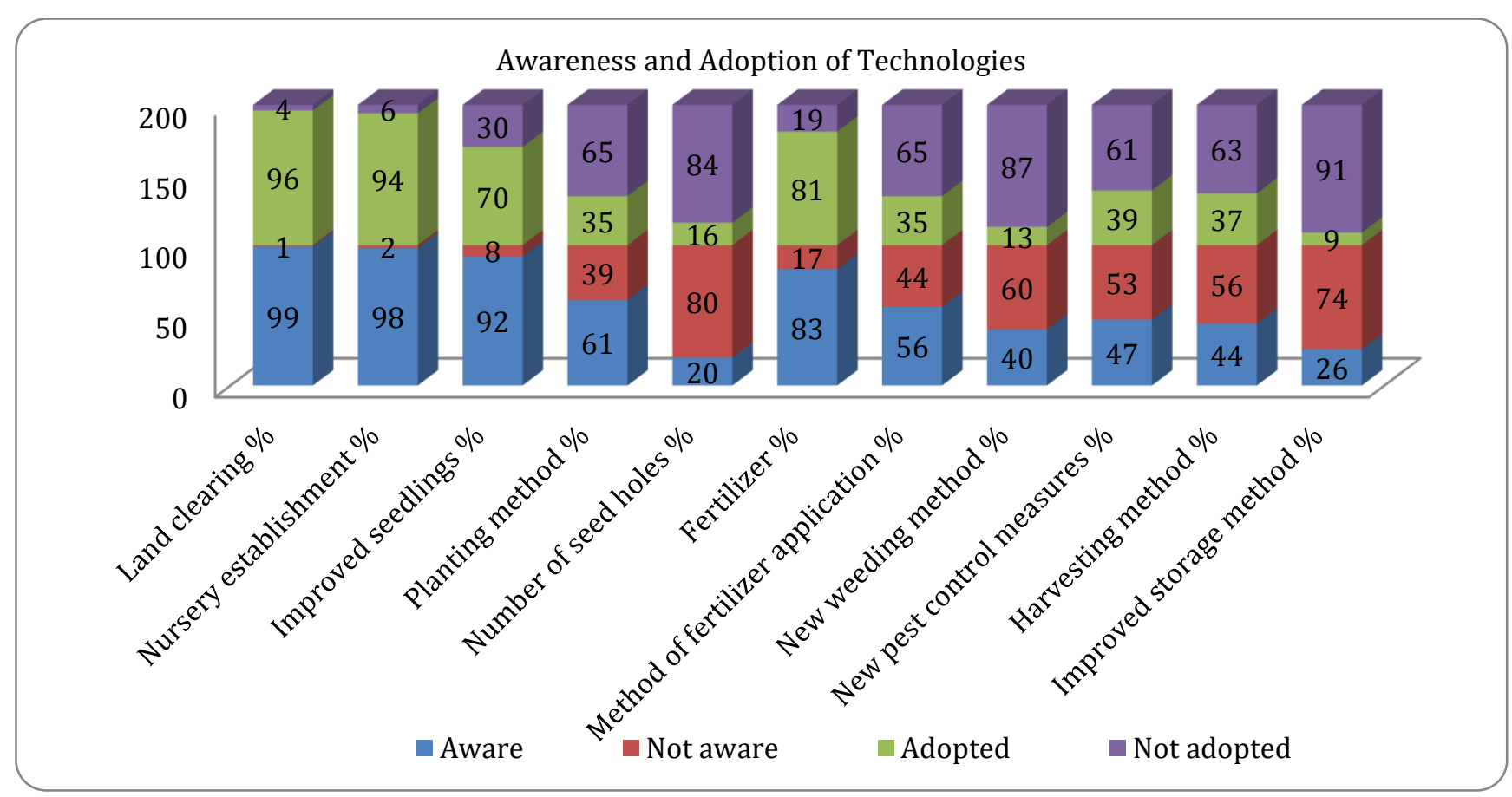

Figure 10. Awareness and adoption of technologies. 
Integrated soil management $\%$

Warehouse receipt system \%

Training in agricultural marketing Collective action \% Credit access \%

Business planning \%

Record keeping \%

Market information \%

Value adding technology $\%$

High value produce $\%$

Post harvest handling \%

Small scale irrigation \%

Fungicide application \%

Herbicide application \%

Proper planting method \%

Proper application of fertilizer \%

Better access to input \%

Improved variety seed used \%

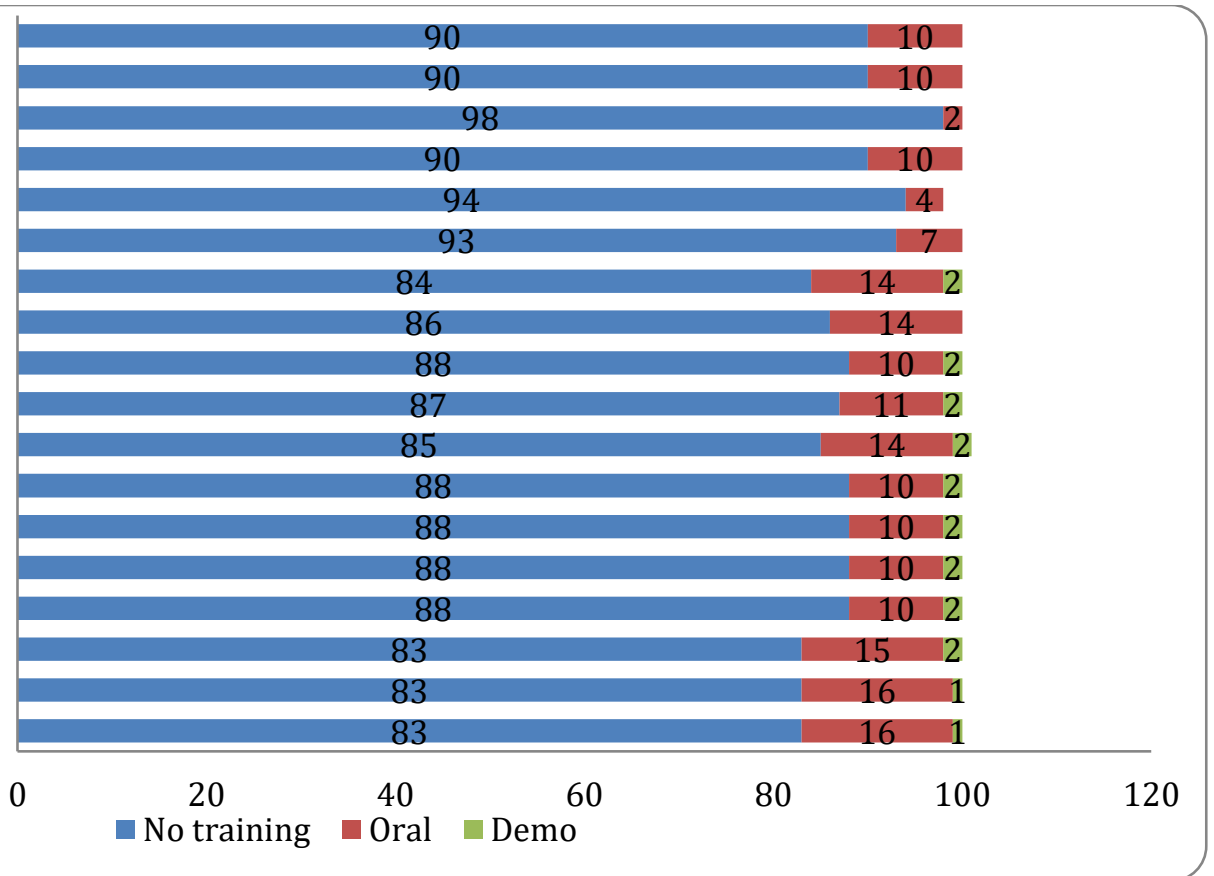

Figure 11. Access to extension and advisory services.

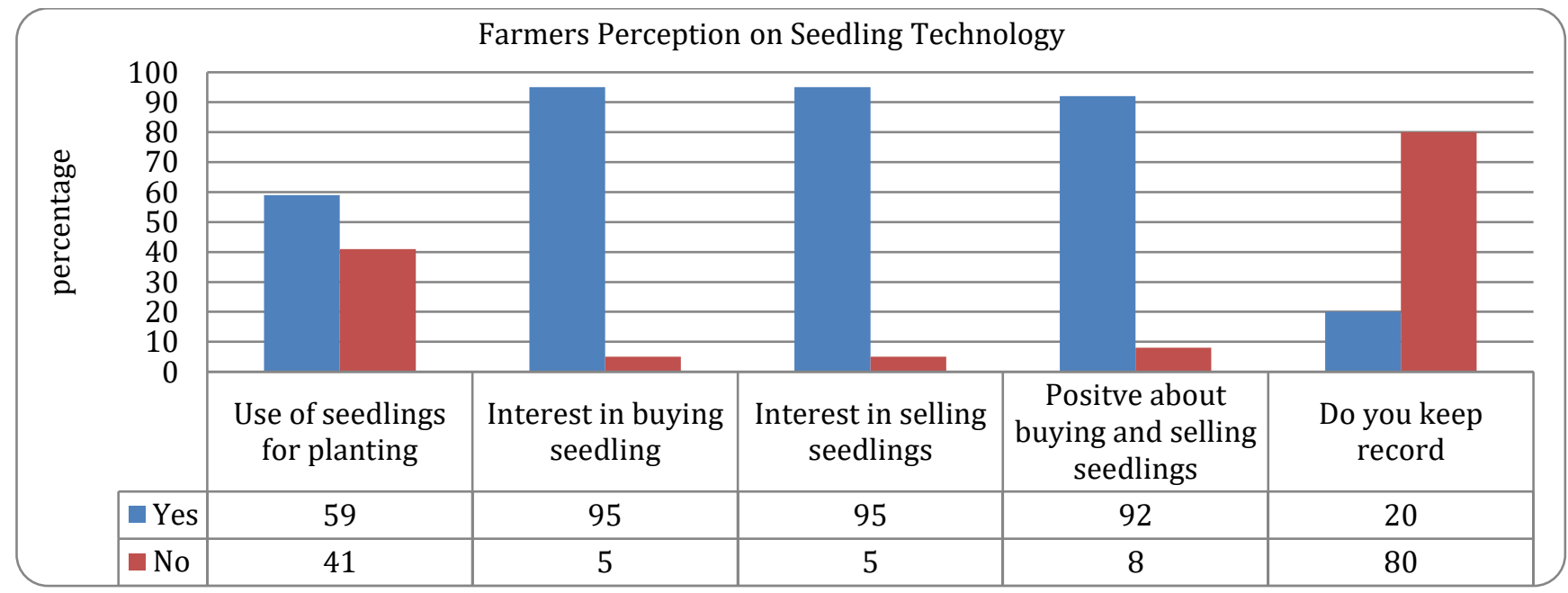

Figure 12. Farmers Perception on Seedling Production Technology.

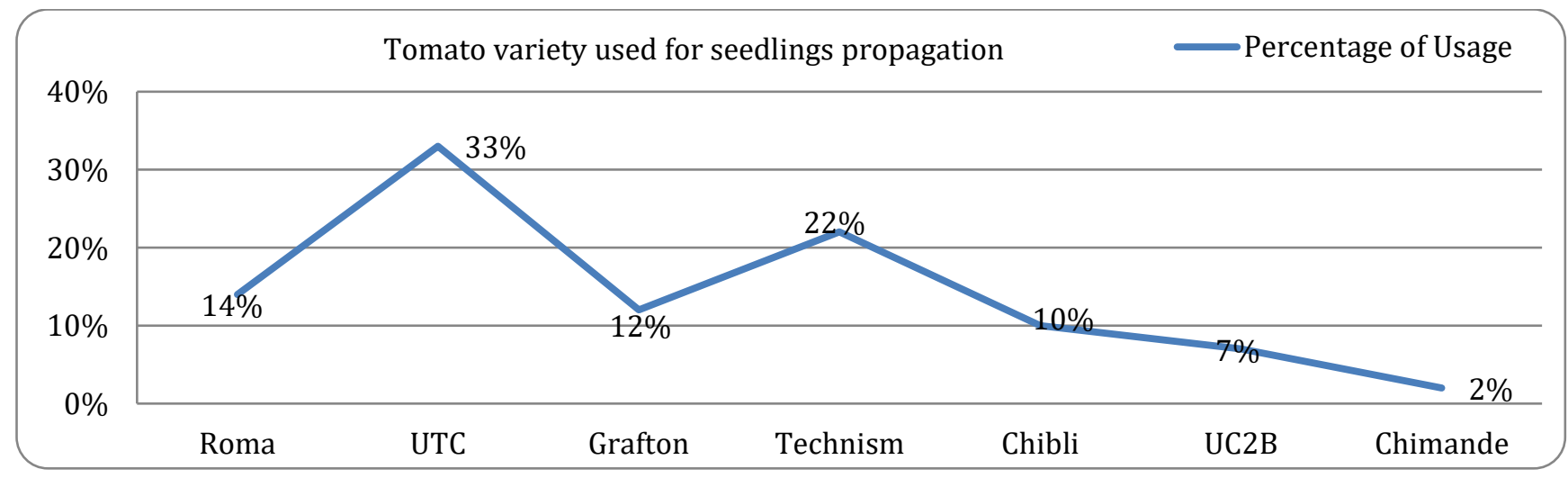

Figure 13. Tomato Variety Used for Seedling Production. 


\author{
Nursery Bed Preparation \\ - Open field $\square$ Nursery trays
}

Nursery trays

2.1

Open field

Figure 14. Nursery bed preparation.

As shown in Figure 2, the main source of income from the area is derived from farming. Although, they also source income from agro-retailing and sales of inputs, but majority $(79 \%)$ of the population source income from farming. With this, farmers will embrace new technologies targeted at increasing yield that will in turn affect their income.

Figure 3 shows that the main crops produced in the sample areas are maize $(36 \%)$, sorghum $(17 \%)$, rice (13\%), Onions $(11 \%)$, millet $(8 \%)$, tomato $(7 \%)$ and lettuce $(1 \%)$. Rice being the staple food of the region. Maize is the main crop with tomato and onion as the main vegetables. This agrees with Awagu et al. (2014) who posited that tomato and onion are important commodities for the preparation of many local dishes in Nigeria, they play major role in providing vitamins and minerals for humans, implying that tomato and onion are very important vegetables in North West Nigeria.

As shown in Figure 4, 52\% of the farmers in the area produces tomato during wet and dry seasons. This shows that tomato will always be available for sales in the market which will keep farmers in business all year round. Figure 5 shows that farmers happen to use different variety of tomato. There is $34 \%$ usage of UTC, $20 \%$ usage of Roma, $15 \%$ usage of chibli, $14 \%$ usage of Technism, $12 \%$ usage of Grafton, $4 \%$ usage of UCUB and only $1 \%$ usage of chimande.

From Figure 6, majority $82 \%$ of the farmers produce their seedlings with the use of recycled seeds, while $12 \%$ buy and transplant and meagre $6 \%$ practice direct seeding. Seeding tomatoes directly into the field is not recommended due to the high cost of hybrid seed and the specific conditions required for adequate germination. However, the use of recycled seeds in tomato seedlings production year in year out is not considered productive and profitable.

As shown in Figure 7, the farmers perform some agricultural activities in the cause of production such as weeding. Farmers patronize several herbicide brands; the herbicide that is highly patronized in the area is Grazon with 31\% usage and an average cost price of $\mathrm{N}$ 1800. $18 \%$ usage of roundup herbicide is the next patronized with cost price of $\mathrm{N} 2400$. The third on the scale of patronage is grass zero with $13 \%$ usage. From this result, it is obvious that farmers are not perturbed with the cost price of herbicide, but they are moved by the effectiveness of the brand as well as joining the bandwagon/majority in the use of product with high market demand.

As shown in Figure 8, the insecticide brands used includes Best, Lara force and Karate with $23 \%, 22 \%$, and $19 \%$ usage and N2300, N2100, and N1800 as average cost price respectively. Crop Protection products play a significant role in keeping food affordable and available. With the use of agrochemicals, food availability can be increased which will lead the food items to be affordable for everyone.

For fertilizer, as shown in Figure 9, farmers patronize Golden N.P.K and Urea with $85 \%$ and $15 \%$ usage and $\mathrm{N} 13,600$ and $\mathrm{N8,000}$ as average cost price respectively. According to the IFDC, about half of the global population is alive as a result of the increased food production provided by the use of mineral fertilizers (Yousaf et al., 2017).

As shown in Figure 10, 99\% of farmers are aware of land clearing technology while $96 \%$ adopted farmers are aware of new/improved seed variety, and $70 \%$ adopted it, it was also observed that the farmers from the survey recycled seeds. As for planting method, $61 \%$ of the farmers are aware while only $35 \%$ adopted. While we have only $20 \%$ of farmers who are aware of number of seed/holes, $16 \%$ out of them adopted it. Next is the knowledge on fertilizer, it was discovered that $83 \%$ of the farmers are aware with $81 \%$ adoption rate, this is in consonance with Barla (2013) who posited that as part of modern technology, the use of fertilizers has been encouraged as it increases the yield from the soil. Thus, higher per hectare consumption of fertilizers is an 
indicator of improved productivity from agriculture. Maiangwa et al. (2010) also in a similar work found out that there is a positive and significant effect of extension contact on adoption of fertilizer and other technologies which is an indication that extension systems must be strengthened to increase farmer knowledge and understanding of mineral fertilizer sources and other related technological options in a timely and accurate manner using the most appropriate communication and training methods.

As shown in Figure 11, 88\% of the farmers do not have access to extension and advisory services. They have not received training in the above areas. However, only $11 \%$ of the farmers got involved in oral training and $1 \%$ in demo training. However, from the result it can be deduced that farmers received more oral training on better access to input (16\%) and improved variety seed used (16\%). This may not yield a positive outcome as productivity can only be increased if farmers adopt good agronomic practices in addition to better access to inputs and improved seed variety. According to Jimoh (2002) findings in the experiment on tomato production carried out at Kabba College of Agriculture in which all these agronomic practices were put in place during the experiment that led to the increase in tomato production in the experimental station.

As shown in Figure 12, looking at the farmers' perception on the use of seedlings for planting, majority (59\%) uses seedlings for planting. However, it was gathered that $95 \%$ of the farmers are interested in buying seedlings if made available. Also, the result shows that $95 \%$ of the farmers are interested in selling tomato seedling to other farmers if given the opportunity. The major reasons why majority of the respondents operate in seedling production were for employment and income generation. This result is in accord with Larinde and Santus (2014), who stated that Small scale private plant nursery enterprise is a selfemployment business that can contribute to substantial employment, income generation and socio-economic development of a state

As shown in Figure 13, 33\% of the tomato seedling produced belongs to the UTC variety, $22 \%$ belongs to Technism, $14 \%$ for Roma, $12 \%$ for Grafton, $10 \%$ for Chibli tomato variety. This means that UTC variety is widely used tomato variety for seedling propagation in the study area. Plum tomatoes (UTC) are long, plumshaped, dense tomatoes grown specifically for making tomato sauce. Plum tomato plants have been bred over hundreds of years to produce the best tomatoes for making tomato sauce (Duford, 2019).

As shown in Figure 14, majority (98\%) of Tomato propagators produce their nurseries in the open fields, while $2 \%$ of the farmers produce in the nursery trays. This agrees with Rabo and Mazadu (2018) who posited that Inadequate finance and water for irrigation of seedlings were the major constraints to nursery enterprise in Bauchi state, Nigeria.

\section{CONCLUSION AND RECOMMENDATIONS}

The study showed that tomato producers are married men and falls within the active age capable of undertaking all tomato seedling production activities. Most of them practiced farming as a major occupation which affords them the opportunity to focus on farming as a means of livelihood. The use of Insecticides and herbicides indicated that the farmers make use of crop protection products in their farms which tend to increase their productivity. Most farmers used recycled UTC tomato variety seeds for planting which resulted to low productivity. It also portrayed that most of the farmers do not have access to extension and advisory services, good agronomic practices and there is low awareness and adoption of tomato seedling technologies. The farmers are interested in buying and selling seedlings to other farmers which is an indication that if the seedlings are made available, it will be viable business in the North west Nigeria. The use of open field nursery for seedlings propagation shows that the farmers are not practicing the modern method of tomato seedlings propagation technology.

Therefore, from this study the following recommendations were made: (1) public and private's sector at all levels must strengthen extension service systems to increase farmers' knowledge and understanding of agricultural technology through provision of tomato seedlings technology and frequent trainings and marketing demos establishment. (2) Seed companies/Inputs Dealers should develop a go-tomarket strategies that will ensure improved/hybrid tomatoes seeds are accessible and affordable across all the villages in the North West region of Nigeria. (3) Seed companies should ensure that seed packages contain recommended agronomic practices to ensure all round effectiveness. (4) Collaboration between farmers, extensionists and researchers in the development of 
tomato seedling technologies in response to today's rapidly changing circumstances would also be extremely useful. (5) Efforts must be made to sensitise farmers on the need to make use of improved seeds for seedling/nursery propagation during planting seasons to avoid the use of recycled seeds which reduces productivity

\section{ACKNOWLEDGEMENTS}

This work was funded by Syngenta Foundation for Sustainable Agriculture-Nigeria. The Technical assistance of Benjamin Osheho, a Corps member is gracefully appreciated.

\section{FUNDING DISCLOSURE}

Syngenta Foundation for Sustainable Agriculture-Nigeria funded the survey.

\section{REFERENCES}

Awagu, E. F., A. M. R and O. F.F. 2014. Assessing the Storage Potential of Some Vegetable Products in Some Selected Areas in Kano State. IOSR Journal of Agriculture and Veterinary Science, 7: 51-59.

Badmus, M. A. and A. O. Olufolaji. 2013. Contribution of urban vegetable farmers to food security: the case of the akinyele local government, oyo state, Nigeria. Acta Horticulturae: 815-20.

Barla, M. 2013. The impact of new agricultural technology on tribal farming: A case study of Ranchi district of Jharkhand state. 9(1), 121131. Journal of Economic and Social development, 9: 121-31.

Duford, J. M. 2019. Plum Tomatoes: All About The Classic Sauce-Making Type of Tomato - Home for the Harvest. https://www.homefortheharvest.com/plumtomatoes/.

Jimoh, U. S. 2002. Evaluation of Different Levels of Organic Fertilizer on Growth, Development and yield of Tomato Unpublished HND Project of Ahmadu Bello University, Kabba College of Agric. Messianen.

Larinde, S. and R. Santus. 2014. Assessment of small scale private plant nursery enterprise in port harcourt, rivers state. Global Journal of BioScience and Biotechnology, 3: 301-11.
Maiangwa, M. G., A. O. Ogungbile, J. O. Olukosi and T. K. Atala. 2010. Adoption of Chemical Fertilizer for Land Management in the North-West Zone of Nigeria. Tropical Agricultural Research and Extension, 10: 33.

Meena, G. and N. Punjabi. 2012. Farmer's perception towards agriculture technology in tribal region of Rajasthan. Rajasthan Journal of Extension Education, 20: 92-96.

NPC. 2018. Nigeria Demographic and Health Survey 2018 - Summary Report [SR264] (dhsprogram.com).

Obayelu, A. E., P. A. Okuneye, A. M. Shittu, C. A. Afolami and A. O. Dipeolu. 2016. Determinants and the perceived effects of adoption of sustainable improved food crop technologies by smallholder farmers along the value chain in Nigeria. Journal of Agriculture and Environment for International Development (JAEID), 110: 15572.

Olayemi, F. F., J. A. Adegbola, E. I. Bamishaiye and A. M. Daura. 2011. Assessment of post-harvest challenges of small scale farm holders of tomotoes, bell and hot pepper in some local government areas of Kano State, Nigeria. Bayero Journal of Pure and Applied Sciences, 3: 39-42.

Onubuogu, G., S. Chidebelu and E. Eboh. 2013. Enterprise type, size and allocative efficiency of broiler production in Imo State, Nigeria. International Journal of Applied Resources and Technologies, 2: 10-19.

Rabo, E. K. and A. E. Mazadu. 2018. Economic Analysis of Seedlings Plant Productions in Nurseries within Bauchi Metropolis in Nigeria. International Journal of Forestry and Horticulture, 4: 8-15.

Syngenta Foundation for Sustainable Agriculture. 2020. Nigeria | Syngenta (syngentafoundation.org).

Ugonna, C., M. Jolaoso and A. Onwualu. 2015. Tomato value chain in Nigeria: Issues, challenges and strategies. Journal of Scientific Research and Reports: 501-15.

Yousaf, M., J. Li, J. Lu, T. Ren, R. Cong, S. Fahad and X. Li. 2017. Effects of fertilization on crop production and nutrient-supplying capacity under riceoilseed rape rotation system. Scientific reports, 7: 1-9. 